\title{
Amyloid imaging and memory change for prediction of cognitive impairment
}

Susan M Resnick*1 and Jitka Sojkova, ${ }^{1,2}$

\begin{abstract}
PET radiotracers for in vivo measurement of $\beta$-amyloid $(A B)$ deposition throughout the brain are contributing to early detection of the neuropathology associated with Alzheimer's disease and enhancing prediction of individuals most likely to develop cognitive impairment and dementia. However, the fact that 30 to $50 \%$ of cognitively normal older adults have varying but detectable levels of $A \beta$ poses challenges and opportunities in using amyloid imaging in research and clinical applications. In this review, we summarize studies of the relationship between $A \beta$ burden and cognitive status in impaired and unimpaired individuals and the relationship between $A \beta$ burden and cognitive function. We conclude by operationalizing the way in which information on imaging-assessed $A \beta$ burden and cognitive performance can be used jointly to improve prediction of clinical outcomes, to enhance understanding of the role of $A \beta$ deposition in cognitive impairment, and to identify factors that promote cognitive resilience in the presence of $A \beta$.
\end{abstract}

The development of positron emission tomography (PET) amyloid imaging radiotracers has allowed the in vivo measurement of fibrillar $\beta$-amyloid $(\mathrm{A} \beta)$ throughout the brain. Amyloid imaging is contributing to the early detection of pathology and diagnosis of Alzheimer's disease (AD), to the selection and therapeutic monitoring of patients in clinical trials, and to differential diagnosis among dementia subtypes. In addition, it is enhancing our understanding of the role of $A \beta$ in the temporal course of disease by allowing prospective assessment of early pathological changes and the cognitive correlates of these changes in $\mathrm{A} \beta$ deposition. PET imaging of fibrillar

\footnotetext{
*Correspondence: resnicks@grc.nia.nih.gov

'Laboratory of Behavioral Neuroscience, NIH Biomedical Research Center, National Institute on Aging, IRP, 251 Bayview Blvd, Room 4B335, Baltimore, MD 21224, USA Full list of author information is available at the end of the article
}

A $\beta$ provides many opportunities for early diagnosis of cognitive impairment and the understanding of disease progression, but the prediction of clinical outcomes in cognitively unimpaired individuals remains challenging.

The large percentage of individuals who have substantial levels of $A \beta$ but remain cognitively normal is a potential limitation in the use of amyloid imaging for prediction of clinical outcomes. Thirty to fifty percent of individuals who are clinically normal at death have sufficient $A \beta$ plaques at autopsy to meet pathological criteria for AD [1,2]. Similarly, PET imaging studies also show that about $30 \%$ [3-7] of cognitively normal individuals have varying levels of increased $A \beta$ on imaging. Some investigators argue that cognitively normal individuals with $\mathrm{AD}$ pathology are in a preclinical stage of AD [8-10]. However, we [11] and others [12] have shown that antemortem cognitive change in this group of 'asymptomatic AD' individuals does not differ significantly from cognitively normal individuals without AD pathology at autopsy, in contrast to the marked memory decline evident in those who develop subsequent cognitive impairment (Figure 1a).

The challenge posed by these asymptomatic $\mathrm{AD}$ individuals in the application of PET A $\beta$ imaging for clinical diagnosis has led some to question whether these tools will be useful in prediction of clinical outcomes. Individuals with elevated $\mathrm{A} \beta$ on PET imaging may not have passed fully through the risk period for AD and represent a heterogeneous group, with some at increased risk for cognitive impairment and others likely to remain healthy (as represented by the autopsy-defined asymptomatic AD group). In this paper, we suggest ways in which information from PET amyloid imaging can be used in combination with cognitive change to improve the utility of these measures for prediction of cognitive decline and impairment and to identify factors that promote cognitive resilience in the presence of $A \beta$ pathology. We first review current evidence demonstrating differences in imaging-assessed $\mathrm{A} \beta$ burden among groups of $\mathrm{AD}$, mild cognitive impairment (MCI) [13], and cognitively normal $(\mathrm{CN})$ individuals. Next, we review cross-sectional and longitudinal studies of associations between $A \beta$ deposition and cognitive performance. Finally, we conclude 

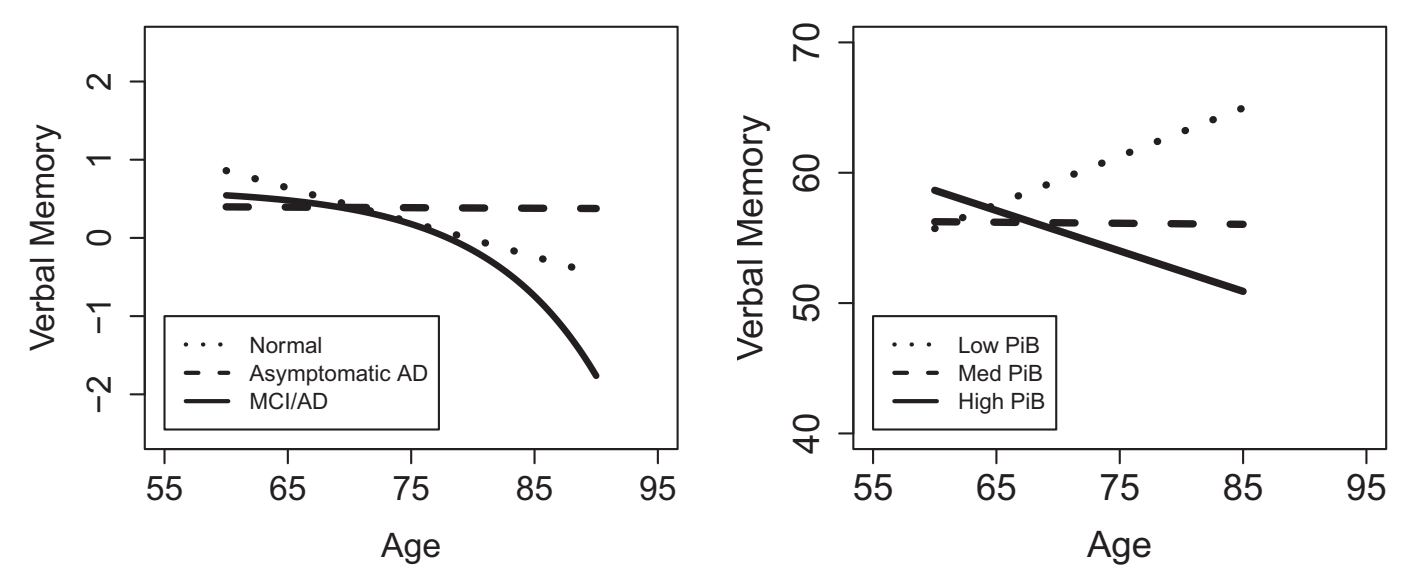

Figure 1. Longitudinal trajectories of verbal memory performance as a function of amyloid pathology. (a) Autopsy studies. (b) In vivo $\left[{ }^{11} \mathrm{C}\right]$ Pittsburgh Compound-B (PiB) imaging studies. (a) Reproduced with premission from Driscoll and colleagues [1 1], showing similar longitudinal trajectories of verbal memory performance (z-scores of free recall on the Cued Selective Reminding Test) in normal individuals with and without Alzheimer's disease (AD) pathology in contrast to marked decline in individuals who later are diagnosed with MCl or AD. (b) Adapted with permission from Resnick and colleagues [6] and shows differences in longitudinal trajectories of verbal memory performance (total immediate free recall on the California Verbal Learning Test) as a function of PiB retention. Note that individuals in the autopsy study are older than those in the imaging studies and are more likely to have passed through the risk period for cognitive impairment. MCl, mild cognitive impairment.

with a discussion of what amyloid imaging in conjunction with cognitive performance can and cannot tell us about prediction of cognitive impairment and resilience. We highlight how information from imaging and neuropsychological assessments can be used in combination to improve prediction of clinical outcomes and to enhance our understanding of the cognitive correlates of $A \beta$ deposition and progression.

\section{Amyloid imaging in cognitive impairment and in healthy older adults}

Imaging with the radioligand $\left[{ }^{11} \mathrm{C}\right]$ Pittsburgh Compound$\mathrm{B}(\mathrm{PiB})$ has provided strong evidence of group differences between cognitively impaired (AD and MCI) and normal $(\mathrm{CN})$ older adults in global as well as regional measures of $A \beta$ deposition (for review, see [14]). It is noteworthy that the level of $\mathrm{A} \beta$ in $\mathrm{MCI}$ individuals who are $\mathrm{PiB}$ positive approaches the level in $\mathrm{AD}$, suggesting either a plateau [15] or a low rate [16] of $A \beta$ accumulation after the appearance of clinical symptoms. Frontal, lateral temporal, and parietal regions show consistent patterns of elevated $A \beta$ in those with cognitive impairment compared with healthy older adults, with more variable findings with respect to group differences in the occipital and striatal regions (for review, see [14]). These global and regional patterns of differences between impaired and $\mathrm{CN}$ individuals are generally consistent across a variety of PET amyloid radiotracers. The majority of studies to date have used $\mathrm{PiB}$, but a number of $\left[{ }^{18} \mathrm{~F}\right]$ radiotracers for amyloid imaging recently have become available and have been applied in imaging studies of AD. These include Florbetaben (BAY94-9172),
Flutemetamol (GE067) and Florbetapir (AV-45), and all show differences between AD patients and controls that are similar in distribution to group differences using $\mathrm{PiB}$ [17-19]. Additional studies are required to provide information on long-term predictive utility of these amyloid imaging tracers, especially in the case of $\mathrm{MCI}$ and preclinical AD in asymptomatic individuals. However, the availability of $\left[{ }^{18} \mathrm{~F}\right]$ ligands, which have a 110 -minute half-life and can be produced for regional distribution, will allow more widespread research and potential clinical applications compared to $\left[{ }^{11} \mathrm{C}\right]$ ligands, which have a 20 -minute half-life requiring on-site radiopharmaceutical production.

Another PET radiotracer that has been used to evaluate AD pathology is $\left[{ }^{18} \mathrm{~F}\right] \mathrm{FDDNP}$. $\left[{ }^{18} \mathrm{~F}\right] \mathrm{FDDNP}$ differs from the other amyloid imaging compounds in several ways. It labels plaques and tangles, as well as alpha-synuclein [20]. Furthermore, the radioactivity signal from this tracer is lower than the signal achieved with more specific $A \beta$ radiotracers, leading to difficulties in quantification [21]. However, an interesting application of this tracer is the potential use of subtraction measures to highlight nonamyloid pathology [22]. By using multiple radiotracers, $\left[{ }^{18} \mathrm{~F}\right]$ FDDNP shows additional binding in the hippocampal formation compared to $\mathrm{PiB}$, perhaps reflecting neurofibrillary tangle pathology [22].

Despite consistent group differences between impaired and $\mathrm{CN}$ individuals, amyloid imaging compounds show varying levels of elevated $A \beta$ across individuals. In studies with $\mathrm{PiB}$, attempts have been made to define values for a $\mathrm{PiB}$ positive study indicating elevated $A \beta$ burden. A variety of cut-points have been used (for 
review, see [14]), but these are dependent on the specific method used for quantification - for example, standard uptake value ratio (SUVR) versus dynamic modeling of the time course of radioactivity in brain. Both cut-points and approaches that examine $A \beta$ as a continuous measure have been used to determine relationships with cognitive status.

Amyloid imaging may be especially useful in distinguishing between individuals with MCI who will progress to dementia and $\mathrm{AD}$ versus those who will not progress to dementia [23-25]. MCI represents a heterogeneous group, with individuals showing either AD-like levels of $\mathrm{A} \beta$ deposition or $\mathrm{CN}$-like levels of $\mathrm{A} \beta$ deposition [25-28]. Approximately one-half of individuals with amnestic MCI [25,29], characterized by memory impairment, have elevated $A \beta$ on imaging and have an increased risk of conversion to AD (see below). MCI individuals without elevated $\mathrm{A} \beta$ have a lower likelihood of progression to $\mathrm{AD}$ $[24,25]$. These individuals may be cases of misdiagnosis, may have different conditions that interfere with cognitive function, or may be false negatives on imaging due to the fact that current radiotracers do not label all $\mathrm{A} \beta$ isoforms [30].

Variability in imaging-assessed amyloid burden is also apparent in older cognitively healthy adults. As noted above, the proportion of PiB-positive individuals has ranged from $20 \%$ in a study by Mintun and colleagues [5] to $47 \%$ in the multicenter study performed through the Alzheimer's Disease Neuroimaging Initiative [4]. Cognitively healthy $\mathrm{PiB}$-positive individuals show a range of values of $\mathrm{PiB}$ that are clearly detectable on imaging but are typically below those observed in $\mathrm{AD}$. To date, the primary factors associated with increased $A \beta$ burden in $\mathrm{CN}$ individuals are older age and Apolipoprotein $\mathrm{E}$ (APOE) $\varepsilon 4$ genotype [7,31]. For example, in the Australian Imaging, Biomarker, and Lifestyle (AIBL) study of 177 healthy controls, $33 \%$ of healthy controls were PiBpositive, with a rate of $65 \%$ in individuals older than 80 years compared with $18 \%$ in individuals aged 60 to 69 years $[7,31]$. Moreover, the rate of elevated $\mathrm{PiB}$ binding was more than double in APOE \&4 gene carriers (49\%) compared with noncarriers (21\%) [7]. Cognitively healthy individuals with elevated amyloid burden likely represent a heterogeneous group with respect to long-term outcome. While some of these individuals will progress to cognitive impairment and $\mathrm{AD}$, others will remain resilient in the face of pathology. The latter group may parallel the group we have called asymptomatic AD at autopsy (and others have called high pathology controls or preclinical AD), because they do not show accelerated cognitive decline despite substantial amyloid pathology [11]. Some investigators attribute this resilience to 'cognitive reserve' [32-34], implying greater neural complexity or plasticity at baseline, but the resilience may also reflect a more general capacity to regain homeostasis across body systems in the face of a variety of ageassociated insults, including $A \beta$ deposition.

\section{Amyloid imaging and cognitive performance}

Investigations of the associations between in vivo measurement of amyloid burden and cognition are necessary to determine the extent and conditions under which elevated amyloid burden is associated with cognitive decline. When data are combined across groups of individuals with $\mathrm{AD}, \mathrm{MCI}$ and $\mathrm{CN}$ older adults, higher $\mathrm{A} \beta$ burden is correlated with lower episodic memory performance $[21,28,35,36]$. These associations are also evident in analyses pooling MCI and AD together [37] and in studies pooling $\mathrm{CN}$ and $\mathrm{AD}$ together [33,38]. Correlations between $\mathrm{A} \beta$ burden and performance in non-memory cognitive domains also have been identified in analyses pooling groups of impaired and unimpaired individuals $[33,38]$. In one study, correlations across diagnostic groups suggested that increased frontal $\mathrm{PiB}$ is associated with lower memory whereas increased parietal $\mathrm{PiB}$ is associated with lower performance on non-memory functions [36].

Associations between in vivo neuropathology and cognitive performance across combined groups of impaired and unimpaired individuals also have been reported using $\left[{ }^{18} \mathrm{~F}\right] \mathrm{FDDNP}$ as the radiotracer [20,39]. In addition to inverse associations between $\left[{ }^{18} \mathrm{~F}\right]$ FDDNP binding and verbal paired associate memory when $\mathrm{CN}$ and $\mathrm{MCI}$ individuals were combined, $\left[{ }^{18} \mathrm{~F}\right] \mathrm{FDDNP}$ was also inversely associated with performance on other cognitive measures, including mental status and digit recall, across all groups [20]. Spatial associations of $\left[{ }^{18}\right.$ F]FDDNP binding with lower performance on tests of episodic memory and frontal lobe function across groups localized to entorhinal, lateral temporal, parietal, orbitofrontal and dorsolateral prefrontal cortex [39]. Mesial temporal associations with $\left[{ }^{18} \mathrm{~F}\right]$ FDDNP may reflect sensitivity to neurofibrillary tangles in these regions.

Although associations between PET imaging measures of neuropathology and memory performance are evident in analyses combining impaired and unimpaired individuals, relationships with memory performance within a diagnostic group are more complex (Tables 1 and 2). As summarized in Table 1, the correlations between crosssectional measures of $\mathrm{A} \beta$ burden using $\mathrm{PiB}$ and cognitive performance in $\mathrm{AD}$ patients tend to be absent to weak $[28,35,37,40]$. In MCI, some but not all studies indicate that higher $\mathrm{A} \beta$ burden is associated with lower performance on tests of episodic memory $[35,37,41]$. A recent study from a larger cohort of $57 \mathrm{MCI}$ participants from the AIBL study on aging showed only a trend to a relationship between higher neocortical $A \beta$ burden and lower long delay free recall performance on the California Verbal Learning Test, a measure of verbal memory [7]. 
Table 1. Cross-sectional associations between PiB-assessed $\beta$-amyloid burden and cognition in $A D$ and $M C I$

\begin{tabular}{|c|c|c|c|c|c|c|}
\hline Study & Year & Sample ${ }^{a}$ & $\begin{array}{l}\text { Number of } \\
\text { subjects }^{\mathrm{a}}\end{array}$ & $\begin{array}{l}\text { Mean } \\
\text { age (SD) }\end{array}$ & Method & Associations between PiB retention and cognitive function \\
\hline Furst et al. [40] & 2010 & $A D$ & 39 & $68.3(10.5)$ & DVR & No association with MMSE or CDR-SOB \\
\hline Forsberg et al. [37] & 2010 & $A D$ & 37 & $67.5(9.2)$ & SUVR & $\begin{array}{l}\text { Higher PiB in bilateral frontal cortices and posterior cingulate gyrus weakly } \\
\text { associated with lower verbal memory (RAVLT) in AD alone }\end{array}$ \\
\hline Grimmer et al. [54] & 2009 & $\begin{array}{l}\text { AD with } \\
\text { AD-typical } \\
\text { FDG scan }\end{array}$ & 32 & $66.9(8.5)$ & SUVR & $\begin{array}{l}\text { Higher PiB in bilateral frontal and anterior cingulate cortex, and lentiform } \\
\text { nucleus }(P \leq 0.05) \text { associated with higher CDR-SOB }\end{array}$ \\
\hline Rowe et al. [28] & 2007 & $A D$ & 17 & $74.0(11.3)$ & DVR & No significant association with long delay verbal recall (CVLT) or MMSE \\
\hline Pike et al. [35] & 2007 & $A D$ & 31 & $74.8(10.2)$ & SUVR & No association with composite score of episodic memory \\
\hline Rowe et al. [7] & 2010 & $\mathrm{MCl}$ & 57 & $75.5(7.5)$ & SUVR & $\begin{array}{l}\text { Higher PiB shows trend with lower long delay verbal recall (CVLT; } r=-0.24 \text {, } \\
P=0.07)\end{array}$ \\
\hline Wolk et al. [25] & 2009 & $\mathrm{MCl}$ & 26 & $70.2(8.8)$ & DVR & $\begin{array}{l}\text { PiB-positive aMCl have lower verbal delayed recall than PiB-negative aMCl } \\
(P<0.01) \text { but PiB-positive were also substantially older }\end{array}$ \\
\hline Lowe et al. [29] & 2009 & $\mathrm{MCl}$ & 23 & $\begin{array}{l}82(\mathrm{aMCl}-) \\
73(\mathrm{aMCl}+)\end{array}$ & SUVR & $\begin{array}{l}\text { No significant memory difference between aMCl-negative and } \\
\text { aMCl-positive (but aMCl-negative substantially older) }\end{array}$ \\
\hline Mormino et al. [41] & 2009 & $\mathrm{PiB}+\mathrm{MCl}$ & 39 & $75.0(7.9)$ & DVR & Higher PiB associated with lower verbal delayed recall (RAVLT; $P=0.05)$ \\
\hline Forsberg et al. [23] & 2008 & $\mathrm{MCl}$ & 21 & $63.3(7.8)$ & SUVR & $\begin{array}{l}\text { Higher PiB in posterior cingulate, frontal, and temporal cortex }(P \leq 0.05) \\
\text { associated with lower composite score of episodic memory }\end{array}$ \\
\hline Pike et al. [35] & 2007 & $\mathrm{MCl}$ & 33 & 70.7(9.6) & SUVR & $\begin{array}{l}\text { Higher PiB associated with lower composite score of episodic memory } \\
(r=-0.6, P<0.001) \text { and remains significant when limited to } \mathrm{aMCl}\end{array}$ \\
\hline
\end{tabular}

an some cases a study subsample. AD, Alzheimer's disease; aMCI, amnestic MCl; CDR-SOB, Clinical Dementia Rating scale Sum of Boxes; CVLT, California Verbal Learning Test; DVR, distribution volume ratio; FDG, fluorodeoxyglucose; $\mathrm{MCl}$, mild cognitive impairment; MMSE, Mini-Mental State Examination; PiB, [1"C]Pittsburgh Compound-B; RAVLT, Rey Auditory Verbal Learning Test; SD, standard deviation; SUVR, standard uptake value ratio.

Associations between $A \beta$ and cognitive performance are even more variable in studies of $\mathrm{CN}$ individuals. Table 2 summarizes findings from cross-sectional studies of $\mathrm{CN}$ older adults. Several investigations have shown negative cross-sectional correlations between $\mathrm{PiB}$ retention and measures of episodic memory [19,41,42], and one study indicated that cognitive reserve, measured by the National Adult Reading Test, may modify this association [33]. However, the largest study of $177 \mathrm{CN}$ adults found no significant cross-sectional correlations with episodic memory [7], suggesting that a few PiBpositive individuals may have a large influence on findings in smaller samples. The varied results across studies highlight the complexity of the relationship between cognitive performance and amyloid deposition at the earliest stages of cognitive decline.

The few longitudinal investigations of cognitive change in relation to $A \beta$ burden have more consistently shown associations for cognitively healthy individuals (Table 2). For example, Villemagne and colleagues [43] reported that greater decline in word list recall was associated with higher $\mathrm{A} \beta$ deposition in nondemented elderly who ultimately progressed to $\mathrm{MCI} / \mathrm{AD}$ but not in individuals who remained cognitively normal [43]. Storandt and colleagues [42] found that elevated $A \beta$ burden was associated with greater longitudinal decline in episodic and working memory, as well as visuospatial ability, and we [6] reported that higher $A \beta$ was associated with greater longitudinal decline in verbal memory (Figure 1b), executive function and mental status, but not visual memory. Our observations of significant relationships between higher $\mathrm{PiB}$ retention and greater cognitive decline in cognitively healthy individuals appear at first glance to conflict with our autopsy findings [11] showing similar longitudinal cognitive trajectories in older adults with and without AD pathology (Figure 1a,b). However, participants in imaging studies are younger and have not passed fully through the risk period for cognitive decline. Thus, cognitively healthy individuals with elevated $A \beta$ on imaging include those who are in a preclinical phase of $\mathrm{AD}$ as well as those who will be resilient and maintain cognitive health.

\section{Amyloid imaging and cognition in prediction of Alzheimer's disease}

There are two ways that amyloid imaging may be useful in combination with cognition in prediction of the likelihood of developing AD. The first involves using amyloid imaging to distinguish among mildly impaired individuals to predict who is likely to progress and who is more likely to remain stable. Table 3 describes the results of initial attempts to use amyloid imaging in predicting outcomes in MCI. The second application combines information on longitudinal cognitive decline with $A \beta$ status to determine which cognitively healthy individuals are at highest risk for progression to impairment and AD. 
Table 2. Associations between $\boldsymbol{\beta}$-amyloid burden and cognition in cognitively normal individuals

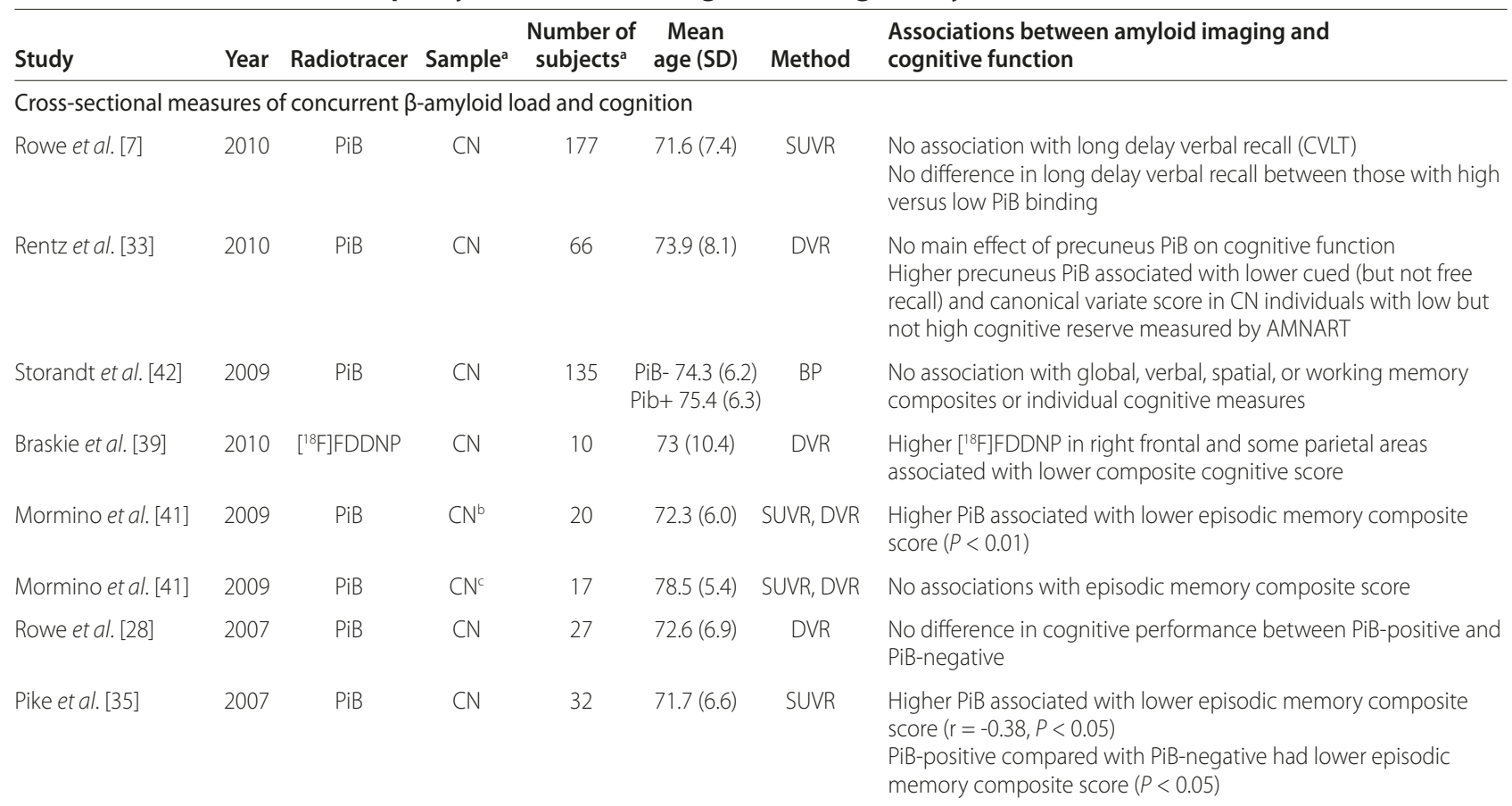

Cross-sectional measures of $\beta$-amyloid load and longitudinal measures of cognition

$\begin{array}{llllll}\text { Resnicketal. [6] } & 2010 & \text { PiB } & \text { CN } & 57 & 78.8(6.2)\end{array}$

$(6 \mathrm{CDR}=0.5)$

\begin{tabular}{|c|c|c|c|c|c|c|}
\hline Storandt et al. [42] & 2009 & $\mathrm{PiB}$ & $\mathrm{CN}$ & 135 & $\begin{array}{l}\text { PiB- } 74.3(6.2) \\
\text { Pib+ } 75.4(6.3)\end{array}$ & $\mathrm{BP}$ \\
\hline Villemagne et al. [43] & 2008 & $\mathrm{PiB}$ & $\begin{array}{c}\text { Stable (S), } \\
\text { declining (D) }\end{array}$ & $\begin{array}{l}24 S \\
10 D\end{array}$ & $\begin{array}{l}S 71.7(6.7) \\
\text { D } 75.5(4.4)\end{array}$ & SUVR \\
\hline
\end{tabular}

Higher PiB associated with greater decline in immediate and delayed verbal recall and MMSE (all $P \leq 0.01$ ) but not visual memory

Associations most pronounced for frontal and lateral temporal cortex, as well as putamen

Higher PiB associated with greater decline in working memory and visuospatial ability

Higher PiB associated with greater decline in word-list recall $(r=-0.78)$ in decliners only

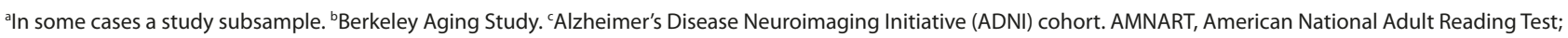
$\mathrm{BP}$, binding potential; CDR, Clinical Dementia Rating scale; CN, cognitively normal; CVLT, California Verbal Learning Test; DVR, distribution volume ratio; MMSE, MiniMental State Examination; PiB, [ $\left.{ }^{1} \mathrm{C}\right]$ Pittsburgh Compound-B; RAVLT, Rey Auditory Verbal Learning Test; SD, standard deviation; SUVR, standard uptake value ratio.

In MCI, A $\beta$ burden assessed by PiB PET has been helpful in distinguishing between individuals who will convert to AD and those who will remain stable [23-25] or develop other forms of dementia. Rates of conversion to $\mathrm{AD}$ in $\mathrm{MCI}$ individuals with a positive amyloid imaging scan are substantially higher than those with a negative $\mathrm{PiB}$ scan, with the latter showing less than $10 \%$ rates of conversion over 3 years $[24,25]$. As described in Table 3, MCI converters may also have different patterns of $\mathrm{PiB}$ amyloid deposition compared to MCI non-converters [24], with higher $\mathrm{PiB}$ retention in posterior cingulate $[23,44]$ and frontal [44] regions. Okello and colleagues [24] identified a subset of PiB-positive MCI individuals who rapidly progressed to $\mathrm{AD}$. Compared to $\mathrm{PiB}$-positive slower MCI converters and nonconverters, the rapid converters had higher $\mathrm{PiB}$ retention in anterior cingulate, frontal, and lateral temporal cortices. In addition, the presence of the APOE $\varepsilon 4$ allele in PiB-positive MCI individuals was associated with higher rates of conversion to AD [24].

In $\mathrm{CN}$ adults, consideration of $\mathrm{A} \beta$ burden alone showed that risk for $\mathrm{AD}$ in $\mathrm{PiB}$-positive individuals was 4.8 times that in PiB-negative $\mathrm{CN}$ individuals over a 2.4-year follow-up [45] (Table 3). However, no studies to date have combined PET measures of $\mathrm{A} \beta$ burden with cognitive performance for prediction of $\mathrm{AD}$ risk in $\mathrm{CN}$ individuals. In our concluding comments, we operationalize the way that cognitive performance, especially on episodic memory tests, can be used in combination with $A \beta$ burden to further increase prediction of $\mathrm{CN}$ individuals who are likely to develop AD versus remain healthy.

\section{Conclusion}

The ability to image brain $\mathrm{A} \beta$ in vivo is advancing our understanding of the neurobiology of cognitive impairment and holds promise as a tool that will contribute to 
Table 3. Amyloid imaging and prediction of conversion to Alzheimer's disease

\begin{tabular}{|c|c|c|c|c|c|c|c|}
\hline Study & Year & Radiotracer & Sample ${ }^{a}$ & $\begin{array}{l}\text { Number of } \\
\text { subjects }^{\mathrm{a}}\end{array}$ & $\begin{array}{c}\text { Mean } \\
\text { age (SD) }\end{array}$ & Method & Findings \\
\hline Okello et al. [24] & 2009 & $\mathrm{PiB}$ & $\mathrm{MCl}$ & 31 & $\begin{array}{l}69.4 \\
(7.9)\end{array}$ & SUVR & $\begin{array}{l}\text { 82\% PiB-positive } \mathrm{MCl} \text { convert to } \mathrm{AD} \text { compared to } 7 \% \text { of } \\
\text { PiB-negative } \mathrm{MCl} \\
47 \% \text { PiB-positive } \mathrm{MCl} \text { who convert to AD within } 1 \text { year have } \\
\text { higher PiB in anterior cingulate and frontal cortex }(P<0.05) \text {, } \\
\text { APOE } \varepsilon 4 \text { is associated with faster conversion rates in } \\
\text { PiB-positive } \mathrm{MCl}(P<0.05)\end{array}$ \\
\hline Wolk et al. [25] & 2009 & $\mathrm{PiB}$ & $\mathrm{MCl}$ & $\begin{array}{l}26 \text { (23 with } \\
\text { follow-up) }\end{array}$ & $\begin{array}{l}70.2 \\
(8.8)\end{array}$ & DVR & 38\% PiB-positive MCl but no PiB- convert to AD over 22 months \\
\hline Morris et al. [45] & 2009 & $\mathrm{PiB}$ & $\mathrm{CN}$ & 159 & $\begin{array}{l}71.5 \\
(8.6)\end{array}$ & $\mathrm{BP}$ & $\begin{array}{l}\text { Higher } \mathrm{PiB} \text { retention predicts progression from CDR } 0 \text { to } \mathrm{MCl} \\
\text { (hazard ratio }=2.74 \text { ) and } \mathrm{AD} \text { (hazard ratio }=4.85 \text { ) over mean } \\
2.4 \text { years }\end{array}$ \\
\hline Koivunen et al. [44] & 2008 & PiB & $\mathrm{aMCl}$ & 15 & $\begin{array}{l}71.1 \\
(7.2)\end{array}$ & $\begin{array}{l}\text { SUVR, } \\
\text { DVR }\end{array}$ & $\begin{array}{l}\text { Elevated PiB in six converters in posterior cingulate and frontal } \\
\text { cortex as well as elevated neocortical score }\end{array}$ \\
\hline Forsberg et al. [23] & 2008 & PiB & $\mathrm{MCl}$ & 21 & $\begin{array}{l}63.3 \\
(7.8)\end{array}$ & SUVR & $\begin{array}{l}\text { Higher } \mathrm{PiB} \text { retention in frontal, parietal, and temporal cortices } \\
(P<0.01) \text { in } \mathrm{MCl} \text { converters than } \mathrm{CN} \text { individuals } \\
\text { Higher PiB retention in posterior cingulate gyrus in } \mathrm{MCl} \\
\text { converters than } \mathrm{MCl} \text { nonconverters }(P<0.01) \\
\text { No difference in } \mathrm{PiB} \text { retention between } \mathrm{MCl} \text { converters and } \mathrm{AD}\end{array}$ \\
\hline Small et al. [20] & 2006 & {$\left[{ }^{18} \mathrm{~F}\right] \mathrm{FDDNP}$} & $\begin{array}{c}\mathrm{AD}, \mathrm{MCl} \\
\mathrm{CN}\end{array}$ & $\begin{array}{l}4 \mathrm{MCl}, \\
8 \mathrm{CN}\end{array}$ & $\begin{array}{l}\text { NA for this } \\
\text { subset }\end{array}$ & DVR & $\begin{array}{l}\text { Three disease progressors had increases in }\left[{ }^{18} \mathrm{~F}\right] \mathrm{FDDNP} \text { between } \\
5.5 \% \text { to } 11.2 \% \text { compared to } \leq 3 \% \text { in nine non-progressors }\end{array}$ \\
\hline
\end{tabular}

aln some cases a study subsample. AD, Alzheimer's disease; aMCl, amnestic $\mathrm{MCl}$; $\mathrm{APOE}$, Apolipoprotein $\mathrm{E}$; $\mathrm{BP}$, binding potential; $\mathrm{CN}$, cognitively normal; $\mathrm{DVR}$, distribution volume ratio; $\mathrm{MCl}$, mild cognitive impairment; NA, not available; PiB, [ $\left.{ }^{11} \mathrm{C}\right]$ Pittsburgh Compound-B; SD, standard deviation; SUVR, standard uptake value ratio.

the detection of early pathological changes and prediction of who will ultimately develop $\mathrm{AD}$ and who will maintain cognitive health. From a number of studies, it is clear that PET amyloid imaging shows robust differences in $\mathrm{A} \beta$ levels among groups of $\mathrm{AD}, \mathrm{MCI}$ and $\mathrm{CN}$ individuals. When groups are combined, associations between higher $A \beta$ and lower cognitive performance, especially episodic memory, emerge consistently across studies. Within diagnostic groups, correlations between $\mathrm{A} \beta$ burden and cognitive performance are less clear in cross-sectional investigations (summarized in Tables 1 and 2). The few longitudinal studies to date that included measures of change in cognitive performance over time provide more convincing evidence that increased $A \beta$ correlates with greater decline in verbal memory, and perhaps other cognitive measures, such as executive function and mental status.

The potential utility of $A \beta$ imaging as a clinical tool for early diagnosis of preclinical AD remains limited by its lower specificity due to the high proportion of PiBpositive $\mathrm{CN}$ individuals $[3,5,28,31,35]$. Additional challenges in interpreting a positive amyloid scan are the presence of amyloid plaques in other forms of dementia, for example, Lewy body disease [28], and the fact that $A \beta$ also binds to intravascular amyloid, as is the case with cerebral amyloid angiopathogy [46]. Further, current radiotracers for $A \beta$ imaging label predominantly fibrillar $\mathrm{A} \beta$ and do not measure soluble forms, providing only a partial quantification of $A \beta$ burden. Despite these limitations, $A \beta$ imaging in combination with information on cognitive function can help inform early detection and diagnosis of $\mathrm{AD}$.

The ways in which joint consideration of $A \beta$ imaging and cognitive function may help inform prediction of $\mathrm{AD}$ and cognitive health are illustrated in Table 4. This simplified table shows that, in the presence of cognitive impairment, $A \beta$ imaging will help distinguish between $\mathrm{A} \beta$-positive individuals with $\mathrm{MCI}$ who are likely to progress to $A D$ versus $A \beta$-negative individuals with $\mathrm{MCI}$ who have a much lower risk of progression. A $\beta$-negative individuals with apparent cognitive impairment may be misdiagnosed as MCI and convert back to normal, may have a different neurodegenerative disorder or other condition, or may be false negative $A \beta$ cases due to a different isoform [30]. Similarly, A $\beta$ imaging may help distinguish between $\mathrm{CN}$ individuals with longitudinal decline in memory who are likely to develop $\mathrm{AD}$ versus those whose memory decline may be associated with other factors, such as other medical conditions or medications. Whereas $\mathrm{A} \beta$-positive $\mathrm{CN}$ individuals with memory decline greater than expected for age are at increased risk for $\mathrm{AD}$, memory declines in older adults who are $A \beta$-negative are more likely attributable to other factors. Finally, $\mathrm{CN}$ individuals who are $\mathrm{A} \beta$-negative and do not show accelerated longitudinal decline in memory can be reassured that they are not likely to develop AD over the next several years. $\mathrm{CN}$ individuals who are $\mathrm{A} \beta$ positive and have stable longitudinal memory 
Table 4. Joint consideration of $\beta$-amyloid and cognition for prediction of cognitive outcomes

\begin{tabular}{llll}
\hline $\boldsymbol{\beta}$-Amyloid & Cognitively impaired/MCl & CN with memory decline & CN without memory decline \\
\hline Positive & Increased risk of $A D^{a}$ & Increased risk of AD & Cognitive resilience ${ }^{\mathrm{b}}$ or preclinical $A D ?$ \\
Negative & Low risk of AD & Low risk of AD & Remain CN
\end{tabular}

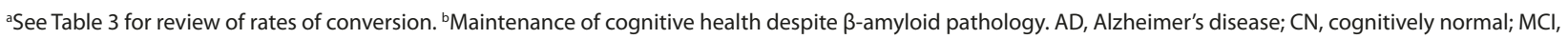
mild cognitive impairment.

performance may represent the group of asymptomatic $\mathrm{AD}$ or may not have reached a threshold of pathology where memory decline is evident. These findings, of course, must be interpreted in the context of an individual's age and APOE genotype, as younger $\mathrm{CN}$ individuals with $A \beta$ pathology may not have passed through the risk period for accelerated cognitive decline and dementia. Longitudinal follow-up studies will determine the time course of the development of $A \beta$ and whether there truly are individuals who are resilient to pathology or in whom the clinical symptoms are delayed. Moreover, comparisons between $A \beta$-positive individuals who have stable memory performance and those who show cognitive decline and impairment may lead to identification of factors that promote cognitive resilience despite pathology. The ability to stratify longitudinal trajectories of memory performance by $A \beta$ will also inform and perhaps revise our definition of what constitutes 'normal aging' in the absence of pathology. Finally, prediction models incorporating other factors, such as APOE genotype, cerebrospinal fluid (CSF) A $\beta$ and Tau, as well as both regional and network-based spatial measures of brain atrophy on MRI [47] may increase sensitivity and specificity for early identification of $\mathrm{AD}$ and cognitive resilience.

In addition to its contributing role in early identification of individuals at greatest risk for AD, amyloid imaging is also aiding in drug development and elucidating the regional distribution and temporal course of the neurobiological changes leading to memory loss and AD. Amyloid imaging informs the selection of participants in therapeutic trials - for example, for anti- $A \beta$ treatments and may be useful in monitoring therapeutic response. In one recent trial, an $8.5 \%$ decline in $A \beta$ level was detected in response to an anti-A $\beta$ treatment [48]. PET amyloid imaging is also being used in combination with CSF and MRI measures to track the temporal course and regional brain changes preceding memory loss. Amyloid deposition is hypothesized to be an early stage of the disease process, with functional and structural brain changes, including hippocampal volume loss, occurring closer to the manifestation of clinical symptoms [49]. Imaging tools provide information throughout the brain, directing attention to the regions showing the earliest amyloid deposition and volumetric changes. In some cases, such as early amyloid deposition in precuneus/posterior
This article is part of a review series on Amyloid Imaging. Other articles in the series can be found online at http://alzres.com/series/ amyloidimaging

cingulate, these imaging findings are focusing more detailed investigation on brain regions that were not included previously in laborious neuropathological evaluations [50,51]. Amyloid imaging also provides the opportunity for prospective assessment of amyloid deposition in relation to changes in cognitive performance and regional brain volumes $[47,52]$. The ability to track pathology over time using both amyloid imaging and CSF measures of A $\beta$ [53] will enhance understanding of the temporal sequence of events in parallel and subsequent to amyloid deposition. Such studies may reveal whether there is some threshold beyond which memory impairment is evident and may identify factors that either render some individuals with substantial pathology resilient to disease or promote a delayed onset of clinical symptoms.

\section{Abbreviations}

$A \beta, \beta$-amyloid; AD, Alzheimer's disease; APOE, Apolipoprotein $E ; C N$, cognitively normal; $C S F$, cerebrospinal fluid; $\mathrm{MCl}$, mild cognitive impairment; $\mathrm{MRI}$, magnetic resonance imaging; PET, positron emission tomography; PiB, $\left[{ }^{11} \mathrm{C}\right]$ Pittsburgh Compound-B.

\section{Competing interests}

The authors declare that they have no competing interests.

\section{Acknowledgements}

This research was supported by the Intramural Research Program of the $\mathrm{NIH}$, National Institute on Aging and N01-AG-3-2124.

\section{Author details}

'Laboratory of Behavioral Neuroscience, NIH Biomedical Research Center, National Institute on Aging, IRP, 251 Bayview Blvd, Room 4B335, Baltimore, MD 21224, USA. 2Russell H Morgan Department of Radiology and Radiological Sciences, Johns Hopkins University School of Medicine, 601 North Caroline Street, Baltimore, MD 21287-0807, USA.

Published: 31 January 2011

\section{References}

1. O'Brien RJ, Resnick SM, Zonderman AB, Ferrucci L, Crain BJ, Pletnikova O, Rudow G, lacono D, Riudavets MA, Driscoll I, Price DL, Martin LJ, Troncoso JC: Neuropathologic studies of the Baltimore Longitudinal Study of Aging (BLSA). J Alzheimers Dis 2009, 18:665-675.

2. Price JL, McKeel DW Jr, Buckles VD, Roe CM, Xiong C, Grundman M, Hansen LA, Petersen RC, Parisi JE, Dickson DW, Smith CD, Davis DG, Schmitt FA, Markesbery WR, Kaye J, Kurlan R, Hulette C, Kurland BF, Higdon R, Kukull W, Morris JC: Neuropathology of nondemented aging: presumptive evidence 
for preclinical Alzheimer disease. Neurobiol Aging 2009, 30:1026-1036.

3. Aizenstein HJ, Nebes RD, Saxton JA, Price JC, Mathis CA, Tsopelas ND, Ziolko SK, James JA, Snitz BE, Houck PR, Bi W, Cohen AD, Lopresti BJ, DeKosky ST, Halligan EM, KlunkWE: Frequent amyloid deposition without significant cognitive impairment among the elderly. Arch Neurol 2008, 65:1509-1517.

4. Jagust WJ, Bandy D, Chen K, Foster NL, Landau SM, Mathis CA, Price JC, Reiman EM, Skovronsky D, Koeppe RA: The Alzheimer's Disease Neuroimaging Initiative positron emission tomography core. Alzheimers Dement 2010, 6:221-229.

5. Mintun MA, Larossa GN, Sheline YI, Dence CS, Lee SY, Mach RH, KlunkWE, Mathis CA, DeKosky ST, Morris JC: [11C]PIB in a nondemented population: potential antecedent marker of Alzheimer disease. Neurology 2006, 67:446-452.

6. Resnick SM, Sojkova J, Zhou Y, An Y, Ye W, Holt DP, Dannals RF, Mathis CA Klunk WE, Ferrucci L, Kraut MA, Wong DF: Longitudinal cognitive decline is associated with fibrillar amyloid-beta measured by [11C]PiB. Neurology 2010, 74:807-815.

7. Rowe CC, Ellis KA, Rimajova M, Bourgeat P, Pike KE, Jones G, Fripp J, TochonDanguy H, Morandeau L, O'Keefe G, Price R, Raniga P, Robins P, Acosta O, Lenzo N, Szoeke C, Salvado O, Head R, Martins R, Masters CL, Ames D, Villemagne VL: Amyloid imaging results from the Australian Imaging, Biomarkers and Lifestyle (AIBL) study of aging. Neurobiol Aging 2010, 31:1275-1283.

8. Hyman BT: The neuropathological diagnosis of Alzheimer's disease: clinical-pathological studies. Neurobiol Aging 1997, 18(4 Suppl):S27-32

9. Morris JC, Storandt M, McKeel DW Jr, Rubin EH, Price JL, Grant EA, Berg L: Cerebral amyloid deposition and diffuse plaques in "normal" aging: Evidence for presymptomatic and very mild Alzheimer's disease. Neurology 1996, 46:707-719.

10. Morris JC: Mild cognitive impairment and preclinical Alzheimer's disease. Geriatrics 2005, Suppl:9-14.

11. Driscoll I, Resnick SM, Troncoso JC, An Y, O'Brien R, Zonderman AB: Impact of Alzheimer's pathology on cognitive trajectories in nondemented elderly. Ann Neurol 2006, 60:688-695.

12. Galvin JE, Powlishta KK, Wilkins K, McKeel DW Jr, Xiong C, Grant E, Storandt M, Morris JC: Predictors of preclinical Alzheimer disease and dementia: a clinicopathologic study. Arch Neurol 2005, 62:758-765.

13. Petersen RC, Morris JC: Mild cognitive impairment as a clinical entity and treatment target. Arch Neurol 2005, 62:1 160-1163; discussion 1167.

14. Sojkova J, Resnick SM: In vivo human amyloid imaging. Curr Alzheimer Res 2011 [Epub ahead of print]

15. KlunkWE, Mathis CA: Amyloid imaging and (what is normal?) aging. In Imaging the Aging Brain. Edited by Jagust WDE. Oxford, USA: Oxford University Press; 2009.

16. Jack CR Jr, Lowe VJ, Weigand SD, Wiste HJ, Senjem ML, Knopman DS, Shiung MM, Gunter UL, Boeve BF, Kemp BJ, Weiner M, Petersen RC; Alzheimer's Disease Neuroimaging Initiative: Serial PIB and MRI in normal, mild cognitive impairment and Alzheimer's disease: implications for sequence of pathological events in Alzheimer's disease. Brain 2009, 132:1355-1365.

17. Vandenberghe R, Van Laere K, Ivanoiu A, Salmon E, Bastin C, Triau E, Hasselbalch S, Law I, Andersen A, Korner A, Minthon L, Garraux G, Nelissen N, Bormans G, Buckley C, Owenius R, Thurfell L, Farrar G, Brooks DJ: (18) F-flutemetamol amyloid imaging in Alzheimer disease and mild cognitive impairment: A phase 2 trial. Ann Neurol 2010, 68:319-329.

18. Wong DF, Rosenberg PB, Zhou Y, Kumar A, Raymont V, Ravert HT, Dannals RF, Nandi A, Brasić JR, Ye W, Hilton J, Lyketsos C, Kung HF, Joshi AD, Skovronsky $\mathrm{DM}$, Pontecorvo MJ: In vivo imaging of amyloid deposition in Alzheimer disease using the radioligand 18F-AV-45 (florbetapir [corrected] F 18). J Nucl Med 2010, 51:913-920.

19. Rowe CC, Ackerman U, Browne W, Mulligan R, Pike KL, O'Keefe G, TochonDanguy H, Chan G, Berlangieri SU, Jones G, Dickinson-Rowe KL, Kung HP, Zhang W, Kung MP, Skovronsky D, Dyrks T, Holl G, Krause S, Friebe M, Lehman L, Lindemann S, Dinkelborg LM, Masters CL, Villemagne VL: Imaging of amyloid beta in Alzheimer's disease with 18F-BAY94-9172, a novel PET tracer: proof of mechanism. Lancet Neurol 2008, 7:129-135.

20. Small GW, Kepe V, Ercoli LM, Siddarth P, Bookheimer SY, Miller KJ, Lavretsky H, Burggren AC, Cole GM, Vinters HV, Thompson PM, Huang SC, Satyamurthy N, Phelps ME, Barrio JR: PET of brain amyloid and tau in mild cognitive impairment. N Engl J Med 2006, 355:2652-2663.

21. Tolboom N, Yaqub M, van der Flier WM, Boellaard R, Luurtsema G, Windhorst AD, Barkhof F, Scheltens P, Lammertsma AA, van Berckel BN: Detection of
Alzheimer pathology In vivo using both 11C-PIB and 18F-FDDNP PET. J Nucl Med 2009, 50:191-197.

22. Shin J, Lee SY, Kim SJ, Kim SH, Cho SJ, Kim YB: Voxel-based analysis of Alzheimer's disease PET imaging using a triplet of radiotracers: PIB, FDDNP, and FDG. Neuroimage 2010, 52:488-496.

23. Forsberg $A$, Engler $H$, Almkvist $O$, Blomquist $G$, Hagman $G$, Wall A, Ringheim $A$, Langstrom B, Nordberg A: PET imaging of amyloid deposition in patients with mild cognitive impairment. Neurobio/ Aging 2008, 29:1456-1465.

24. Okello A, Koivunen J, Edison P, Archer HA, Turkheimer FE, Någren K, Bullock R, Walker Z, Kennedy A, Fox NC, Rossor MN, Rinne JO, Brooks DJ: Conversion of amyloid positive and negative $\mathrm{MCl}$ to $\mathrm{AD}$ over 3 years. An 11C-PIB PET study. Neurology 2009, 73:754-760.

25. Wolk DA, Price JC, Saxton JA, Snitz BE, James JA, Lopez OL, Aizenstein HJ, Cohen AD, Weissfeld LA, Mathis CA, Klunk WE, De-Kosky ST: Amyloid imaging in mild cognitive impairment subtypes. Ann Neurol 2009, 65:557-568.

26. Li Y, Rinne JO, Mosconi L, Pirraglia E, Rusinek H, DeSanti S, Kemppainen N, Någren K, Kim BC, Tsui W, de Leon MJ: Regional analysis of FDG and PIB-PET images in normal aging, mild cognitive impairment, and Alzheimer's disease. Eur J Nucl Med Mol Imaging 2008, 35:2169-2181.

27. Price JC, Klunk WE, Lopresti BJ, Lu X, Hoge JA, Ziolko SK, Holt DP, Meltzer CC, DeKosky ST, Mathis CA: Kinetic modeling of amyloid binding in humans using PET imaging and Pittsburgh Compound-B. J Cereb Blood Flow Metab 2005, 25:1528-1547.

28. Rowe CC, Ng S, Ackermann U, Gong SJ, Pike K, Savage G, Cowie TF, Dickinson KL, Maruff P, Darby D, Smith C, Woodward M, Merory J, Tochon-Danguy H, O'Keefe G, Klunk WE, Mathis CA, Price JC, Masters CL, Villemagne VL: Imaging beta-amyloid burden in aging and dementia. Neurology 2007, 68:1718-1725

29. Lowe VJ, Kemp BJ, Jack CR Jr, Senjem M, Weigand S, Shiung M, Smith G, Knopman D, Boeve B, Mullan B, Petersen RC: Comparison of 18F-FDG and PiB PET in cognitive impairment. J Nucl Med 2009, 50:878-886.

30. Rosen RF, Ciliax BJ, Wingo TS, Gearing M, Dooyema J, Lah JJ, Ghiso JA, Levine $\mathrm{H}$, 3rd, Walker LC: Deficient high-affinity binding of Pittsburgh compound B in a case of Alzheimer's disease. Acta Neuropathol 2010, 119:221-233.

31. Morris JC, Roe CM, Xiong C, Fagan AM, Goate AM, Holtzman DM, Mintun MA: APOE predicts amyloid-beta but not tau Alzheimer pathology in cognitively normal aging. Ann Neurol 2010, 67:122-131.

32. Stern $Y$ : What is cognitive reserve? Theory and research application of the reserve concept. J Int Neuropsychol Soc 2002, 8:448-460.

33. Rentz DM, Locascio JJ, Becker JA, Moran EK, Eng E, Buckner RL, Sperling RA, Johnson KA: Cognition, reserve, and amyloid deposition in normal aging. Ann Neurol 2010, 67:353-364.

34. Chételat G, Villemagne VL, Pike KE, Baron JC, Bourgeat P, Jones G, Faux NG, Ellis KA, Salvado O, Szoeke C, Martins RN, Ames D, Masters CL, Rowe CC; Australian Imaging Biomarkers and Lifestyle Study of Ageing (AIBL) Research Group: Larger temporal volume in elderly with high versus low betaamyloid deposition. Brain 2010, 133:3349-3358.

35. Pike KE, Savage G, Villemagne VL, Ng S, Moss SA, Maruff P, Mathis CA, Klunk WE, Masters CL, Rowe CC: Beta-amyloid imaging and memory in nondemented individuals: evidence for preclinical Alzheimer's disease. Brain 2007, 130:2837-2844

36. Tolboom N, van der Flier WM, Yaqub M, Koene T, Boellaard R, Windhorst AD, Scheltens P, Lammertsma AA, van Berckel BN: Differential association of [11C]PIB and [18F]FDDNP binding with cognitive impairment. Neurology 2009, 73:2079-2085.

37. Forsberg A, Almkvist O, Engler H, Wall A, Langstrom B, Nordberg A: High PIB retention in Alzheimer's disease is an early event with complex relationship with CSF biomarkers and functional parameters. Curr Alzheimer Res 2010, 7:56-66.

38. Roe CM, Mintun MA, D'Angelo G, Xiong C, Grant EA, Morris JC: Alzheimer disease and cognitive reserve: variation of education effect with carbon 11-labeled Pittsburgh Compound B uptake. Arch Neurol 2008, 65:1467-1471

39. Braskie MN, Klunder AD, Hayashi KM, Protas H, Kepe V, Miller KJ, Huang SC Barrio JR, Ercoli LM, Siddarth P, Satyamurthy N, Liu J, Toga AW, Bookheimer SY, Small GW, Thompson PM: Plaque and tangle imaging and cognition in normal aging and Alzheimer's disease. Neurobiol Aging 2010, 31:1669-1678.

40. Furst AJ, Rabinovici GD, Rostomian AH, Steed T, Alkalay A, Racine C, Miller BL, Jagust WJ: Cognition, glucose metabolism and amyloid burden in Alzheimer's disease. Neurobiol Aging 2010 [Epub ahead of print].

41. Mormino EC, Kluth JT, Madison CM, Rabinovici GD, Baker SL, Miller BL, 
Koeppe RA, Mathis CA, Weiner MW, Jagust WJ: Episodic memory loss is related to hippocampal-mediated beta-amyloid deposition in elderly subjects. Brain 2009, 132:1310-1323.

42. Storandt M, Mintun MA, Head D, Morris JC: Cognitive decline and brain volume loss as signatures of cerebral amyloid-beta peptide deposition identified with Pittsburgh compound B: cognitive decline associated with Abeta deposition. Arch Neurol 2009, 66:1476-1481.

43. Villemagne VL, Pike KE, Darby D, Maruff P, Savage G, Ng S, Ackermann U, Cowie TF, Currie J, Chan SG, Jones G, Tochon-Danguy H, O'Keefe G, Masters $\mathrm{CL}$, Rowe CC: Abeta deposits in older non-demented individuals with cognitive decline are indicative of preclinical Alzheimer's disease. Neuropsychologia 2008, 46:1688-1697.

44. Koivunen J, Pirttilä T, Kemppainen N, Aalto S, Herukka SK, Jauhianen AM, Hänninen T, Hallikainen M, Någren K, Rinne JO, Soininen H: PET amyloid ligand [11C]PIB uptake and cerebrospinal fluid beta-amyloid in mild cognitive impairment. Dement Geriatr Cogn Disord 2008, 26:378-383.

45. Morris JC, Roe CM, Grant EA, Head D, Storandt M, Goate AM, Fagan AM, Holtzman DM, Mintun MA: Pittsburgh compound B imaging and prediction of progression from cognitive normality to symptomatic Alzheimer disease. Arch Neurol 2009, 66:1469-1475.

46. Johnson KA, Gregas M, Becker JA, Kinnecom C, Salat DH, Moran EK, Smith EE, Rosand J, Rentz DM, Klunk WE, Mathis CA, Price JC, Dekosky ST, Fischman AJ Greenberg SM: Imaging of amyloid burden and distribution in cerebral amyloid angiopathy. Ann Neurol 2007, 62:229-234.

47. Davatzikos C, Xu F, An Y, Fan Y, Resnick SM: Longitudinal progression of Alzheimer's-like patterns of atrophy in normal older adults: the SPARE-AD index. Brain 2009, 132:2026-2035.

48. Rinne JO, Brooks DJ, Rossor MN, Fox NC, Bullock R, Klunk WE, Mathis CA, Blennow K, Barakos J, Okello AA, Rodriquez Martinez de Liano S, Liu E, Koller M, Gregg KM, Schenk D, Black R, Grundman M: 11C-PiB PET assessment of change in fibrillar amyloid-beta load in patients with Alzheimer's disease treated with bapineuzumab: a phase 2, double-blind, placebo-controlled, ascending-dose study. Lancet Neurol 2010, 9:363-372.

49. Jack CR Jr, Knopman DS, Jagust WJ, Shaw LM, Aisen PS, Weiner MW, Petersen RC, Trojanowski JQ: Hypothetical model of dynamic biomarkers of the Alzheimer's pathological cascade. Lancet Neurol 2010, 9:119-128.

50. lacono D, O'Brien R, Resnick SM, Zonderman AB, Pletnikova O, Rudow G, An Y, West MJ, Crain B, Troncoso JC: Neuronal hypertrophy in asymptomatic Alzheimer disease. J Neuropathol Exp Neurol 2008, 67:578-589.

51. Riudavets $M A$, lacono $D$, Resnick $S M, O$ 'Brien $R$, Zonderman $A B$, Martin $\sqcup$, Rudow G, Pletnikova O, Troncoso JC: Resistance to Alzheimer's pathology is associated with nuclear hypertrophy in neurons. Neurobiol Aging 2007, 28:1484-1492.

52. Aisen PS: Predictors of progression in the ADNI-MCl cohort. Alzheimers Dementia 2010, 6:S63.

53. Fagan AM, Mintun MA, Mach RH, Lee SY, Dence CS, Shah AR, LaRossa GN, Spinner ML, Klunk WE, Mathis CA, DeKosky ST, Morris JC, Holtzman DM: Inverse relation between In vivo amyloid imaging load and cerebrospinal fluid Abeta42 in humans. Ann Neurol 2006, 59:512-519.

54. GrimmerT, Henriksen G, Wester HJ, Forstl H, Klunk WE, Mathis CA, Kurz A, Drzezga A: Clinical severity of Alzheimer's disease is associated with PIB uptake in PET. Neurobiol Aging 2009, 30:1902-1909.

doi:10.1186/alzrt62

Cite this article as Resnick SM, Sojkova J: Amyloid imaging and memory change for prediction of cognitive impairment. Alzheimer's Research \& Therapy 2011, 3:3. 